\title{
Consideração sobre o idoso aposentado: uma intervenção da Terapia Cognitivo-Comportamental como instrumento de preparação à aposentadoria
}

\author{
Tatiana Lima Both", Débora Rita Kujawa**, Maria Isabel Wobeto*, Viviane Savaris**
}

\section{Resumo}

Este artigo apresenta uma revisão de literatura sobre o idoso e o processo da aposentadoria. No intuito de auxiliar o idoso nesse processo, buscou-se desenvolver um programa de preparação para a aposentadoria, a qual ocorre frequentemente na velhice e, em virtude do aumento da expectativa de vida, requer reorganização dos investimentos antes empregados no trabalho. Em razão da longevidade, o status de aposentado será uma condição que acompanhará o indivíduo durante longos anos. Nesse sentido, cabe-lhe replanejar sua vida, visto que no trabalho encontrava um espaço de reconhecimento social e pertencimento. Sendo assim, tem-se como objetivo desenvolver algumas intervenções fundamentadas na Terapia Cognitivo-Comportamental (TCC), pois se acredita que suas técnicas auxiliam os idosos a fazerem uma realocação de seus recursos, contribuindo para melhor qualidade de vida após a aposentadoria. O programa de planejamento para a aposentadoria auxiliará o aposentado a preparar-se para essa fase de mudanças, fazendo uma reorganiza- ção de sua rotina para melhor aproveitar o tempo, desenvolvendo atividades que contribuam para a saúde física e mental, seja em um novo trabalho, seja em situações de lazer ou descanso.

Palavras-chave: Idoso. Aposentadoria. Intervenção. Trabalho.

\section{Introdução}

A população idosa no Brasil tem uma expectativa de vida de 73 anos, superando a marca de 15 milhões de pessoas com 60 anos ou mais. Em 2050, o país terá uma igualdade entre jovens e idosos, e a expectativa de vida será de 81 anos. Apesar disso, a Organização das Nações Unidas (2002) indica que a taxa de dependência dos aposentados da classe economicamente ativa tende a cair durante as próximas décadas, de modo

* Psicóloga com especialização em Terapia de Casal e Família (2011), especialização em Humanização e Gestão do SUS (2009), mestrado em Psicologia Social e Institucional (UFRGS, 2004). Professora da Faculdade Meridional - Imed e psicóloga da Secretaria Municipal de Saúde de Passo Fundo. E-mail: tatiboth@imed. edu.br. Rua Senador Pinheiro, 304 - Passo Fundo, CEP 99070-220, Bairro Rodrigues.

** Acadêmicas de Psicologia da Faculdade Meridional IMED.

$\hookrightarrow$ Recebido em setembro de 2012 - Aprovado em outubro de 2012.

$\rightarrow$ doi:10.5335/rbceh.2012.037 
que, em 2050, haverá apenas três trabalhadores para sustentar um aposentado. (FRANÇA; SOARES, 2009).

Os dados dessa estatística são preocupantes, pois o número de aposentados está em constante crescimento. A preocupação está associada ao fato de que a aposentadoria é um fator contribuinte para a fragilização psíquica do idoso, visto que traz mudanças significativas em sua vida. $O$ desligamento da rotina competitiva de trabalho, o desligamento dos colegas, a diminuição da renda financeira, a perda do status social, entre outras mudanças que surgem com a aposentadoria, podem acarretar sérios prejuízos mentais para o aposentado, uma vez que o trabalho é um fator determinante para o desenvolvimento humano, pois é a partir dele que o sujeito constrói sua identidade e produz sentido à sua existência como ser social.

Esse quadro também é relatado por Rodrigues et al. (2005), para quem a aposentadoria pode levar a perdas materiais, psicológicas e sociais capazes de acarretar uma diminuição da autoestima e da motivação e, por consequência, um adoecimento mental, refletindo em crises depressivas, alcoolismo, ansiedade e até mesmo suicídio.

Diante disso, o presente artigo tem como objetivo identificar as consequências da aposentadoria, as perdas e os significados que o sujeito lhe atribui e, a partir disso, buscar intervenções baseadas em técnicas da Teoria Cognitivo-Comportamental (TCC), com vistas a contribuir na qualidade de vida, bem como na saúde emocional do idoso após a privação das atividades ocupacionais.

\section{Metodologia}

Este estudo, de caráter descritivo, foi realizado por meio de revisão de literatura, através de consultas a artigos científicos e livros sobre a temática da aposentadoria. Com base nos estudos bibliográficos e no fichamento do material, buscou-se apontar técnicas da TCC possíveis de serem aplicadas em grupo de pessoas que estão prestes a aposentar-se, visto que são facilitadoras para a preparação do sujeito para esse momento.

\section{Significados da aposentadoria}

O trabalho corresponde a uma fonte de prazer que engloba diversas atividades de acordo com os interesses de cada pessoa. Todavia, nem todos os trabalhadores tiveram a oportunidade de escolher sua profissão. É nítida a influência das famílias e dos amigos nessa escolha, embora existam muitas pessoas aliciadas em empregos por questões de sobrevivência. Outros, por sua vez, não dispuseram de recursos financeiros para uma melhor educação, sentindo mais dificuldade de inserir-se no mercado de trabalho. Mesmo sem obter satisfação com o trabalho, alguns tiveram um único emprego na vida, passando muitos anos desenvolvendo um determinado papel sem talvez conhecer sua verdadeira vocação. (FRANÇA, 2009). 
O trabalho é considerado, sob o ponto de vista social, o principal regulador da organização da vida humana. Também é determinador de algumas exigências, tais como cumprimento de horários, atividades, estabelecimento de relacionamentos pessoais, razão pela qual ocupa um lugar fundamental na vida das pessoas. Com isso, a perda do trabalho pode causar sérios prejuízos ao indivíduo, bem como desorientação emocional, desestruturação e sentimento de inutilidade. (ZANELLI; SILVA, 1996).

A relação que o homem estabelece com o trabalho contribui para a construção da sua identidade pessoal. $\mathrm{Na}$ convivência diária no trabalho, pode-se observar que as pessoas são referências por trabalharem em determinada empresa, com determinada marca, e assim por diante. Aidentidade profissional está relacionada ao autorreconhecimento, que representa a maneira como o próprio indivíduo se reconhece e como é visto pelo outro. Diante disso, a aposentadoria pode ser incorporada de forma prejudicial, afetando a estrutura psíquica e manifestando-se por meio de sintomas como ansiedade, depressão, irritabilidade e insatisfação generalizada, o que leva à redução na qualidade de vida.

De acordo com Mendes et al. (2005), a aposentadoria provoca uma crise no indivíduo, pois, com o afastamento da vida competitiva, a autoestima e a sensação de ser útil reduzem-se. Em um primeiro momento, o idoso tende a mostrar-se satisfeito com a aposentadoria, pela possibilidade de descansar, mas com o de- correr do tempo passa a sentir-se inútil. Esse processo pode representar um problema para o aposentado, causando-lhe angústia e isolamento social, bem como um sentimento de exclusão, tornando difícil sua adequação ao mundo em que vive. Outro fator que a maioria dos idosos enfrenta é uma diminuição na sua renda mensal, o que afeta diretamente sua qualidade de vida.

Pode-se dizer que, para muitos, a aposentadoria significa a liberação de atividades rotineiras e desgastantes, um período caracterizado pelo descanso; já para outros, constitui um momento difícil, na medida em que, frente à falta do trabalho, instala-se uma sensação de vazio existencial. É importante que as diferenças sejam observadas e trabalhadas, pois somente assim a aposentadoria será uma fase da vida aguardada com satisfação.

\section{A aposentadoria e 0 afastamento da dinâmica social}

Com a chegada da aposentadoria, geralmente, percebe-se uma preocupação por parte do indivíduo. Para Linari (2004), a principal dificuldade no enfrentamento da aposentadoria dá-se pelo fato de que nós seres humanos, ao longo da existência, somos submetidos a um processo educativo que nos faz desenvolver capacidades para desempenhar papéis voltados para o trabalho e, quando a fase produtiva entra em decadência ou acaba, aos poucos também a autonomia social vai se perdendo e inicia-se um processo 
de adaptação à aposentadoria, muitas vezes doloroso e até inaceitável.

Todos nós passamos por transições em nosso processo de envelhecimento, de bebê para criança, de criança para adolescente, e assim por diante. Nessa transição, sempre ocorrem perdas e afastamentos de certas coisas com as quais estávamos adaptados. Com o envelhecimento, essas perdas e afastamentos tornam-se ainda mais recorrentes por motivos de incapacidade física, emocional, cognitiva, entre outras.

A teoria do afastamento foi a primeira a tentar explicar o processo de envelhecimento e todas as mudanças que ocorrem com o indivíduo e com a sociedade. Ela propõe que o envelhecimento seja um processo de afastamento universal e inevitável tanto para o idoso quanto para a sociedade. Considera que existe uma reciprocidade de afastamento entre ambos. Assim como é importante para possibilitar a entrada dos jovens no mundo do trabalho, a teoria do afastamento também é necessária para a entrada do idoso na aposentadoria. Porém, tal movimento sempre acontece com certo custo ou ressentimento. (NERI, 2005).

Com o afastamento das atividades de seu trabalho, o idoso depara-se com muito tempo livre, antes ocupado pelas atividades que faziam parte de seu dia a dia. Durante o período produtivo de sua vida, a pessoa que conseguiu desenvolver suas atividades com sucesso terá um sentimento de dever cumprido, mas, caso não tenha alcançado suas expectativas no trabalho, terá sentimentos de inca- pacidade, chegando a um momento em que provavelmente não terá mais tempo nem condições para fazê-lo. Ao chegar à aposentadoria, o idoso que teve maior satisfação com os resultados de seu trabalho, possivelmente, terá, também, mais vontade para ocupar seu tempo de aposentadoria com a realização de novas atividades. Para De Nardi e Oliveira,

Os papéis assumidos descrevem o quanto o indivíduo continua envolvido em papéis significativos, atividades relevantes e decisivas, que lhe pareçam interessantes. A vulnerabilidade para a depressão estaria relacionada com o grau de investimento nesses papéis. A velhice representa o tempo de transição de papéis assumidos socialmente $\mathrm{e}$ da autovalidação, o que pode funcionar como um disparador de problemas emocionais. (2011, p. 511).

$\mathrm{O}$ isolamento na velhice pode acontecer em virtude da falta de novas perspectivas, diante de rupturas, términos ou perdas. A aposentadoria pode ser um fator de afastamento quando, o idoso, na ausência da rotina anterior, não encontra atividades para a ocupação do tempo livre. Assim, poderia não haver motivação para relacionar-se fora dos muros do aposento, e as perdas dos laços sociais acabariam por diminuir a interação social, não permitindo à pessoa processar novas informações e se reconhecer no diálogo com o outro. Dessa forma, é provável uma tendência cada vez maior ao isolamento. Pode-se supor, igualmente, que, na falta de novas informações, a linguagem torna-se empobrecida e pouco interessante ao ouvinte. Se a pessoa passa a sentir o desinteresse do outro em 
virtude de um discurso repetitivo, pode procurar o isolamento.

A teoria da atividade, segundo Doll et al. (2007), pode ser descrita pelas tarefas que surgem na vida das pessoas em determinados períodos. Caso a realização dessas tarefas seja feita com sucesso, o indivíduo terá felicidade e êxito em afazeres posteriores; caso contrário, restarão somente a infelicidade e a reprovação pela sociedade.

Assim, as teorias do afastamento e da atividade explicam como ocorrem as relações sociais na velhice. O idoso irá privar-se de algumas atividades, e de certa forma o processo de isolamento é natural. O "velho" aproxima-se da morte, e as pessoas, muitas vezes, internalizam que, ao chegarem a essa idade, já não precisam mais lutar para viver.

Verifica-se que a interação comunicativa é um fator importante para a integração social; do contrário, a tendência é o isolamento e a solidão, aumentando as chances de a sensação de inutilidade instalar-se. Por isso, a atividade investida de valor, o contato e a interação são importantes para o bem-estar psicológico, auxiliando no interesse de manter-se ativo e inserido no contexto social.

Preferir viver uma vida mais isolada, mais restrita ao lar pode ser uma opção do idoso. Porém, é imprescindível que essa escolha seja livre e não decorra de uma decepção ou da falta de objetivos de vida para investir energia e tempo. De qualquer forma, é importante ressaltar que, de acordo com Neri (2000) e Cachio- ni (1998 apud NOGUEIRA et al., 2009), cada pessoa tem um processo de envelhecimento diferente, que varia segundo a cultura, o contexto social, político, econômico e as experiências individuais ao longo de sua história de vida.

Alvarenga et al. (2009), por sua vez, afirmam que os valores intrínsecos ao próprio sujeito possibilitarão o enfrentamento das perdas e as condições de adaptar-se às novas situações de vida. Assim, se ao longo dos anos a pessoa foi capaz de construir outras fontes de satisfação além do trabalho, torna-se mais fácil o enfrentamento da fase de aposentado.

Para auxiliar na promoção de vivências mais satisfatórias na continuidade da trajetória de vida após a aposentadoria, procurou-se desenvolver intervenções nas técnicas de Terapia Cognitivo-Comportamental capazes de contribuir para o bem-estar emocional do aposentado, no sentido de prepará-lo para as mudanças diante do processo do envelhecimento e do advento da aposentadoria.

\section{Desenvolvimento do programa de preparação para a aposentadoria baseado nas técnicas da Terapia Cognitivo-Comportamental}

A aposentadoria é mais uma etapa da vida, que, por um motivo ou outro, mais cedo ou mais tarde, deve ser enfrentada. Essa etapa produz mudança, como qualquer outra fase. Por isso, é 
importante a preparação para a entrada na aposentadoria, pois, quando acontece essa preparação, o indivíduo consegue desfrutar melhor dessa nova fase em que está se inserindo. Conforme Pacheco e Carlos (2011), quando o aposentado não consegue realizar uma preparação para a ausência do trabalho ao qual dedicou anos de sua vida, pode desenvolver sintomas depressivos, por não conseguir replanejar seu projeto de vida de forma que se sinta socialmente útil. Sua autoestima pode ser reduzida, levando-o a interpretar esse momento como um fracasso pessoal.

Nessa perspectiva, o planejamento para a aposentadoria é importante porque torna possível a reorganização do tempo para que o idoso abarque novas experiências na vida familiar, no lazer, na vida sociocomunitária e até mesmo em um novo trabalho, seja ele remunerado ou voluntário, durante o tempo em que estiver aposentado. Assim, esse planejamento possibilita ao idoso um enfrentamento mais objetivo das condições frustrantes às quais muitos ficam expostos quando chegam à aposentadoria. (ALVARENGA et al., 2007).

Percebe-se a grande importância da preparação para a aposentadoria como motivadora para a qualidade de vida do idoso durante essa fase. Quando a aposentadoria chega sem ter sido planejada, podem surgir dificuldades na adaptação às novas circunstâncias, gerando, muitas vezes, negativismo, falta de disposição, baixa autoestima, isolamento social, di- ficuldade de ocupar o tempo que antes era dedicado ao trabalho.

Em pesquisa com professores universitários aposentados, Moreira (2011) traz como um dos pontos de discussão a aposentadoria como geradora de sensação de inutilidade ou incapacidade, caso o trabalho seja compreendido como manancial de satisfação e vitalidade e a aposentadoria represente a extinção dessa fonte. Outra pesquisa com essa mesma população conclui que a preparação para a aposentadoria oportuniza 0 redimensionamento da vida para novas perspectivas, ressignificando e reorganizando prioridades. (BOTH; CARLOS, 2005). A realização da preparação para aposentadoria possibilita, assim, projetar e programar novas formas de prazer e gratificação. Pode-se dizer que a preparação para essa etapa permite uma transição mais tênue, oferecendo um maior controle sobre a própria vida.

Verifica-se, então, o quanto é premente pensar em instrumentos de preparação para a aposentadoria, pois os estudos mostram o quanto o trabalho produz vínculos sociais, espaços de comunicação e valorização do trabalhador. Nesse sentido, apresentam-se, na sequência, possíveis formas de intervir junto ao trabalhador para que ele possa conduzir sua aposentadoria de maneira menos impactante. Utilizam-se, para tanto, técnicas de intervenção da TCCG, a qual enfatiza a estrutura, o foco, a aquisição de habilidades cognitivas e comportamentais. Essas técnicas possibilitam 
que o próprio grupo gere sua resposta adaptativa, oportunizando o convívio de pessoas que vivenciam o mesmo processo de organização de sua vida, aumentando o grupo de amizades, muito importante para o período da aposentadoria.

Segundo Knapp (apud OLIVEIRA et al., 2011), o objetivo da TCC em grupo é fazer que cada integrante do grupo seja seu próprio terapeuta e se prepare para enfrentar, de maneira adaptativa, situações de estresse que possam surgir ao longo da vida. Nessa mesma perspectiva, Zanelli (2000) diz que a preparação para a aposentadoria procura auxiliar os participantes a desenvolverem habilidades para lidar com as ansiedades oriundas desse período. Percebe-se, dessa forma, o quanto as técnicas da Terapia Cognitivo-Comportamental aplicadas em grupo são pertinentes para a situação de preparação para a aposentadoria.

$\mathrm{O}$ momento introdutório dos encontros com o grupo de futuros aposentados deve privilegiar o rapport inicial, que é um processo de boa comunicação, utilizado para estabelecer o vínculo de confiança, permitindo que o indivíduo expresse suas ideias e preocupações e que seja compreendido pelos demais integrantes. (GONÇALVES, 2009).

Com relação ao profissional em psicologia que trabalhará com o grupo, é importante que este consiga fazer intervenções que possibilitem às pessoas em preparação para a aposentadoria o desenvolvimento de boas expectativas quanto ao futuro, bem como a aceitação de cada fase que estão vivendo, principalmente a da aposentadoria. Várias técnicas podem ser aplicadas para a valorização do indivíduo, a fim de possibilitar a construção de uma boa qualidade de vida na sua aposentadoria. Uma dessas técnicas tem como objetivo desenvolver a escuta, que é muito importante para conhecer a história de vida de cada integrante e a sua relação com o trabalho. Nesse momento, o indivíduo pode expor o que gosta de fazer e quais seus planos para a aposentadoria, enquanto o terapeuta identifica sentimentos e pensamentos do sujeito diante da preparação para essa etapa. Assim, é possível avaliar a existência de sentimentos de insegurança, de inutilidade e incapacidade de realizar qualquer outra atividade. Esses são considerados pensamentos automáticos, que, segundo Knapp, "podem ocorrer antes mesmo da situação em si, como no caso das expectativas que a pessoa tem com uma situação". (2004, p. 134). Na sequência, é possível verificar se ocorrem a catastrofização (predizer o futuro de maneira negativa) e a rotulação (fixar um único rótulo em si mesmo). (BECK, 1997). Identificando-se a ocorrência de pensamentos distorcidos, como catastrofização e rotulação, cabe ao terapeuta do grupo trabalhar esses pensamentos por meio de técnicas específicas da TCC, procurando desfazê-los.

Após a identificação dos pensamentos automáticos, também se pode identificar as crenças nucleares. Beck (1997) explica que, feita a identificação de uma 
crença importante, na qual o paciente acredita fortemente, o terapeuta pode trabalhá-la, utilizando uma crença específica como exemplo. As crenças nucleares, que geralmente são desenvolvidas e carregadas pelo sujeito desde a infância, podem apresentar-se de forma mais intensa no momento da aposentadoria, levando-o a sentir-se sozinho e desamparado. As crenças nucleares podem ser de desamor (desmerecimento de amor dos outros), desamparo (sentimento de incompetência) e desvalor (significado negativo da própria natureza da pessoa). O autor explica que há uma extensão de crenças potenciais que podem ser adotadas, as quais não são inatas, mas aprendidas. Para trabalhá-las, é possível utilizar a colaboração do grupo, o qual pode relatar o que pensa a respeito da crença de cada membro que o compõe.

Depois de ter identificado os pensamentos automáticos e as crenças nucleares, passa-se a trabalhar as mudanças de pensamento, para que o sujeito possa identificar o que é real e o que é oriundo de seus pensamentos. Assim, o objetivo das intervenções nessa etapa é mudar algumas crenças nucleares, descatastrofizar situações extremas e desenvolver na pessoa um sentimento de segurança de si mesmo. Conforme Wright, Basco e Thase (2008), o futuro incerto traz muitas previsões catastróficas, as quais, comumente, são influenciadas pelas distorções cognitivas, situação que deve ser identificada pelo terapeuta, que pode ajudar o paciente a desenvolver meios de enfrentar uma situação temida se ela se tornar real.

Para detectar, demonstrar e possibilitar a revisão sucessiva de pensamentos distorcidos, a técnica da seta descendente é um facilitador. (KNAPP, 2004; LEAHY, 2006). A questão disparadora poderia ser "o aposentado é?", seguida por perguntas geradas com base nas respostas dos participantes, levantando conceitos e motivos da sua construção, de modo a identificar crenças que, anteriormente enraizadas, sustentam a visualização de seu futuro.

Outra atividade de grande valia é a tarefa de casa. Algumas atividades propostas como tema de casa podem ser utilizadas como ocupação do tempo após a aposentadoria, podendo os familiares agir como coterapeutas, participando das atividades propostas. Conforme Knapp (2004), a finalidade da tarefa de casa é que o paciente consiga educar-se para colher dados, avaliar seus pensamentos e suas crenças e, dessa forma, mudar seus pensamentos e testar novos comportamentos. Quando aplicada, a tarefa de casa deve ser retomada na sessão seguinte, e, havendo dificuldade de adesão nas atividades propostas, estará demonstrada a falta de comprometimento do indivíduo em relação ao grupo ou ao momento que ele vivencia.

No intuito de iniciar uma experimentação com a tarefa de casa, utiliza-se a programação de atividades com previsão de prazer e habilidades. (KNAPP, 2004). Escolhendo uma atividade a que preten- 
dem dedicar-se no futuro, os trabalhadores devem prever o quanto de prazer acreditam que obterão ao realizá-la e que habilidade supõem ter para executá-la. Após, devem realizar a atividade, revelando, posteriormente, para o grupo se as expectativas foram condizentes com a vivência. Essa experiência oportuniza uma aproximação com a situação futura para reavaliação ou manutenção dos planos.

Sabe-se que, com a perspectiva da aposentadoria, podem ocorrer mudanças significativas na administração do tempo e nas relações familiares. Em razão disso, é importante que também se desenvolva a chamada psicoeducação com o grupo que está se preparando para a aposentadoria. Figueiredo et al. (2009) sugerem a psicoeducação para orientar e familiarizar o paciente em relação ao problema ou à situação que está vivenciando no momento. No grupo de preparação para a aposentadoria, deve-se focar no processo de transição do indivíduo da vida ativa para a aposentadoria, fazendo-o compreender a etapa que passará a viver e suas implicações. Cabe ao terapeuta fazer o grupo funcionar de forma que seus membros auxiliem-se mutuamente no processo e possam compreender as diferenças que irão sentir em suas vidas, seja quanto à organização do tempo, seja com relação ao fator psicológico, conduzindo-os a desenvolver um suporte para suportar as drásticas mudanças que ocorrerão.

Associadas à psicoeducação, podem ser promovidas palestras informativas sobre assuntos relacionados ao processo de entrada na aposentadoria, além de temas diversos que sejam de interesse dos participantes e úteis para a fase em que se encontram. Os participantes podem interagir, para que consigam tirar suas dúvidas, inclusive sugerindo assuntos ligados à questão. Essas palestras podem abranger relatos de aposentados que conseguiram reorganizar a nova fase de vida e que a consideram fonte de vantagens. Os conteúdos abordados nas palestras servem, enfim, para auxiliar o indivíduo na reflexão acerca de novas perspectivas.

Alguns fatores considerados importantes por Bieling e McCabe (apud OLIVEIRA et al., 2008) no trabalho com grupos terapêuticos também podem ser observados e desenvolvidos com grupos de preparação para a aposentadoria: o otimismo, que é a esperança na superação do problema; a inclusão, que é o aumento da consciência de um problema comum a todos no grupo, reduzindo o isolamento; o aprendizado grupal, que é a estimulação do aprendizado; a remoção do foco em si mesmo, quando se transfere o foco do indivíduo para o grupo; a modificação de padrões desajustados de relacionamento, que é a aprendizagem corretiva de interações interpessoais disfuncionais; a coesão grupal, que é o fortalecimento do vínculo entre os membros de um grupo, promovendo mudanças cognitivas e comportamentais; o processamento emocional no contexto grupal, que se efetiva quando se permite no 
grupo um espaço para a livre expressão.

Na finalização do programa, propõe-se que cada integrante relate sua experiência, informando como se sente com essa preparação. Nesse momento, a escuta do terapeuta é muito importante, pois, caso identifique que algum integrante não está preparado para a aposentadoria, deve encaminhá-lo para uma psicoterapia individual. Ao terapeuta cabe, ainda, estimular o grupo para que utilize algumas das técnicas aprendidas na terapia também após a aposentadoria.

É possível que, durante o programa de preparação para a aposentadoria, algumas dificuldades venham a atrapalhar o andamento do trabalho, tais como a desistência de alguns membros do grupo, a falta de assiduidade aos encontros, problemas de saúde e, até mesmo, a depressão antecipada, por estarem se aproximando do momento de aposentarem-se.

\section{Considerações finais}

Considerando o processo natural de envelhecimento da pessoa, faz-se necessário pensar estratégias que a auxiliem a chegar à velhice com qualidade de vida, tendo possibilidade de usufruir da assistência adequada oferecida pelo sistema social onde se insere. Para tanto, percebe-se que a preparação para a aposentadoria é uma das estratégias necessárias para a manutenção da qualidade de vida e da saúde mental do indivíduo.
Nessa perspectiva, a preparação para a aposentadoria deve tornar-se uma prática presente em todos os ambientes de trabalho, oferecendo às pessoas que se aproximam dessa experiência técnicas que possibilitem a reorganização do dia a dia sem o trabalho, a fim de que continuem sentindo-se úteis, visto que a sociedade, muitas vezes, considera 0 idoso como improdutivo.

Desse modo, a TCC pode auxiliar o idoso na preparação para a aposentadoria, uma vez que lhe permite identificar seus pensamentos distorcidos sobre essa fase, levando-o a mudar seu comportamento e, assim, ocupar seu tempo livre da melhor forma possível ao aposentar-se. Conclui-se, assim, que as técnicas da TCC oferecem ao aposentado novas estratégias para sua adaptação a essa fase da vida.

Consideration of the retired elderly: an intervention of CognitiveBehavioral Therapy as a means of preparation for retirement

\section{Abstract}

A review of literature on the elderly and retirement process is carried out. A program of retirement planning intervention is shown in order to assist the elderly in this process. Retirement that often occurs in old age and due to the increase in life expectancy requires reorganization of investments before employed at work. Longevity of a retired status is a condition that is carried out for long years. In this sense it is necessary to retrace life, since the work has been a social recognition and belonging. 
Thus, it has been aimed to develop some interventions based on cognitive-behavioral therapy (CBT) because it is believed that their techniques assist the elderly to make a reallocation of its resources, contributing to better quality of life after retirement. With the implementation of the retirement planning intervention, it is expected to help the elderly so one can prepare for this phase and thereafter seizes this moment the most convenient way, either through leisure activities with a new labor or own rest.

Keywords: Elderly people. Retirement. Intervention. Labor.

\section{Referências}

ALVARENGA, L. N. et al. Repercussões da aposentadoria na qualidade de vida do idoso. Revista da Escola de Enfermagem da USP, São Paulo, v. 43, n. 4, p. 796-802, dez. 2007.

ALVARENGA, L. N. et al . Repercussões da aposentadoria na qualidade de vida do idoso. Revista da Escola de Enfermagem da USP, São Paulo, v. 43, n. 4, p. 796-802, dez. 2009. Disponível em: <http://www.scielo.br/ scielo.php?script=sci_arttext\&pid=S0080$-62342009000400009 \& \operatorname{lng}=\mathrm{en} \& \mathrm{nrm}=\mathrm{iso}>$. Acesso em: 29 jun. 2013.

BECK, S. J. Terapia cognitiva: teoria e prática. Porto Alegre: Artmed, 1997.

BOTH, T. L.; CARLOS, S. A. Jubilamento: o interdito de uma vida de trabalho e suas repercussões na velhice. Revista Brasileira de Ciências do Envelhecimento Humano, Passo Fundo, v. 2, n. 1, p. 31-42, jan./jun. 2005.

CACHIONI, M. Envelhecimento bem-sucedido e participação numa Universidade para a Terceira Idade: a experiência dos alunos da Universidade São Francisco. 1998. 104 f. Tese (Doutorado) - Universidade Estadual de Campinas, Campinas, 1998.

DOLL, J. et al. Atividade, desengajamento, modernização: teorias sociológicas clássicas sobre o envelhecimento. Estudos Interdis- ciplinares sobre o Envelhecimento, Porto Alegre, v. 12, n. 1 p. 7-33, 2007.

FIGUEIREDO, Â. et al. O uso da psicoeducação no tratamento do transtorno bipolar. Revista Brasileira de Terapia Comportamental e Cognitiva, Campinas, v. 6, n. 1, p. 15-24, 2009.

FRANÇA, L. E. F. P.; SOARES, D. H. P. Preparação para a aposentadoria como parte da educação ao longo da vida. Psicologia: Ciência e Profissão, Brasília, v. 29, n. 4, p. 738-751, dez. 2009.

FRANÇA, L. H. F. P. Influências sociais nas atitudes dos "top" executivos em face da aposentadoria: um estudo transcultural. Revista Administração Contemporânea, Curitiba, v. 13, n. 1, p. 17-35, jan./mar. 2009.

GONÇALVES, A. S. A PNL como ferramenta de desenvolvimento humano. 2009. $42 \mathrm{f}$. Trabalho de Conclusão de Curso (Pós-Graduação em Psicologia) - Instituto Superior de Ciências da Saúde, Salvador, 2009.

KNAPP, P. Principais técnicas. In:

(Org.). Terapia cognitivo-comportamental na prática psiquiátrica. Porto Alegre: Artmed, 2004. p. 133-158.

LEAHY, R. L. Técnicas de terapia cognitiva: manual do terapeuta. Porto Alegre: Artmed, 2006.

LINARI, J. A. Programa pré-aposentadoria: o recomeço de uma nova vida - crise ou oportunidade? O caso Cesp. 2004. 196 f. Dissertação (Mestrado em Gerontologia) - Universidade Católica de São Paulo, São Paulo, 2004.

MENDES, M. R. S. S. B. et al. A situação social do idoso no Brasil: uma breve consideração. Acta Paulista de Enfermagem, São Paulo, v. 18, n. 4, p. 422-426, 2005.

MOREIRA, J. O. Imaginários sobre aposentadoria, trabalho, velhice: estudo de caso com professores universitários. Psicologia em Estudo, Maringá, v. 16, n. 4, p. 541-550, out./dez. 2011.

NARDI, T. C.; OLIVEIRA, R. G. A Terapia cognitivo-comportamental e o envelhecimen- 
to. In: ANDRETTA, I.; OLIVEIRA, M. S. (Org.). Manual prático de terapia cognitivo-comportamental. São Paulo: Casa do Psicólogo, 2008. p. 608.

NERI, A. L. Palavras-chave em gerontologia. 2. ed. Campinas, SP: Alínea, 2005.

NERI, A. L.; FREIRE, S. A. E por falar em boa velhice. Campinas, SP: Papirus, 2000.

NOGUEIRA, E. J. et al. Rede de relações sociais e apoio emocional: pesquisa com idosos. Iniciação Científica Cesumar, Maringá, v. 11, n. 1, p. 65-70, jan./jun. 2009.

OLIVEIRA, M. S. et al. Terapia cognitivo-comportamental em grupos. In: ANDRETTA, I.; OLIVEIRA, M. S. (Org.). Manual prático de Terapia Cognitivo-Comportamental. São Paulo: Casa do Psicólogo, 2011. p. 439-454.

PACHECO, J. L.; CARLOS, S. A. Educação, trabalho e aposentadoria. In: FREITAS, E. V. (Org.). Tratado de geriatria e gerontologia. 3. ed. Rio de Janeiro: Guanabara Koogan, 2011.

RODRIGUES, M. et al. A preparação para a aposentadoria: o papel do psicólogo frente a essa questão. Revista Brasileira de Orientação Profissional, São Paulo, v. 6, n. 1, p. 53-62, jun. 2005.

WRIGHT, H. J.; BASCO, R. M.; THASE, E. M. Aprendendo a terapia cognitivo-comportamental: um guia ilustrado. Porto Alegre: Artmed, 2008.

ZANELLI, J. C. O programa de preparação para aposentadoria como um processo de intervenção ao final de uma carreira. Revista de Ciências Humanas, Florianópolis, Edição Esp. Temática, p. 157-176, 2000.

ZANELLI, J. C.; SILVA, N. Programa de preparação para a aposentadoria. Florianópolis: Insular, 1996. 